\title{
Correlates of menstrual cycle characteristics among nulliparous Danish women
}

This article was published in the following Dove Press journal:

Clinical Epidemiology

17 August 2013

Number of times this article has been viewed

\author{
Kristen A Hahn' \\ Lauren A Wise ${ }^{1,2}$ \\ Anders H Riis ${ }^{3}$ \\ Ellen M Mikkelsen ${ }^{3}$ \\ Kenneth J Rothman ${ }^{1,4}$ \\ Kristen Banholzer ${ }^{\prime}$ \\ Elizabeth E Hatch' \\ 'Department of Epidemiology, \\ Boston University School of Public \\ Health, Boston, MA, USA; ${ }^{2}$ Slone \\ Epidemiology Center, Boston \\ University, Boston, MA, USA; \\ ${ }^{3}$ Department of Clinical Epidemiology, \\ Aarhus University Hospital, Aarhus, \\ Denmark; ${ }^{4}$ RTI Health Solutions, \\ Research Triangle Park, NC, USA
}

Correspondence: Kristen A Hahn Department of Epidemiology, Boston University School of Public Health, 715 Albany St, Boston, MA 021।8, USA

Tel +l 6176387784

Fax + I 6176384458

Email kahahn@bu.edu
Objective: We examined the association between lifestyle factors and menstrual cycle characteristics among nulliparous Danish women aged 18-40 years who were participating in an Internet-based prospective cohort study of pregnancy planners.

Methods: We used cross-sectional data collected at baseline to assess the association of age, body mass index (BMI), physical activity, alcohol and caffeine consumption, and smoking with the prevalence of irregular cycles, short ( $\leq 25$ days) and long ( $\geq 33$ days) cycles, and duration and amount of menstrual flow. We used log-binomial and multinomial logistic regression to estimate prevalence ratios and $95 \%$ confidence intervals.

Results: Low physical activity and heavy alcohol consumption were associated with an increased prevalence of irregular periods. High BMI, smoking, and caffeine and alcohol consumption were related to an increased prevalence of short menstrual cycles and heavy menstrual bleeding. Women in their mid-to-late thirties had shorter and lighter menstrual flow, but a lower prevalence of irregular cycles, compared with women 18-25 years of age.

Discussion: In this study, increased age, high BMI, and sedentary behavior were associated with menstrual-pattern irregularities. These factors may influence the balance and level of endogenous hormones conducive to optimal menstrual function.

Keywords: menstrual cycle, body mass index, alcohol drinking, smoking, caffeine, physical activity, menstruation

\section{Introduction}

Among women of reproductive age, normal menstrual function depends on the complex interaction between the hypothalamic-pituitary-ovarian axis and endogenous hormones. ${ }^{1}$ Alterations in these hormones can affect menstrual cycle characteristics, such as cycle length, regularity, and bleeding patterns. Women with abnormal menstrual cycles may have a higher risk of cardiovascular disease, type 2 diabetes, osteoporosis, infertility, and breast and endometrial cancers. ${ }^{2-9}$ Thus, it is important to understand whether, and to what extent, modifiable lifestyle factors affect normal menstrual cycle function. Previous studies have suggested associations between smoking, caffeine, alcohol, body mass index (BMI), and exercise and menstrual cycle factors such as cycle length and regularity, but findings are inconsistent. ${ }^{10-21}$ The underlying mechanisms connecting lifestyle factors to menstrual function are unclear, but are likely due to alterations in hormonal patterns, which in turn predict the occurrence and timing of ovulation and growth of the endometrial lining.

We conducted a cross-sectional analysis of correlates of four menstrual cycle characteristics (regularity, cycle length, and duration and intensity of menses) among 
nulliparous women from a cohort of pregnancy planners in Denmark.

\section{Methods}

\section{Study population}

We studied participants enrolled from 2007-2011 in the Danish Web-based Pregnancy Planning Study ("SnartGravid"), an Internet-based prospective cohort study of women planning a pregnancy. Eligibility criteria and recruitment methods have been described in detail elsewhere. ${ }^{22-24}$ Briefly, eligible women were aged 18-40 years, Danish residents, in a stable relationship with a male partner, had been attempting to conceive for $\leq 12$ cycles, and were not receiving fertility treatment. The baseline questionnaire collected information on demographics, reproductive and medical history, and lifestyle and behavioral factors. Participants were initially randomized to receive either a short-form or long-form baseline questionnaire, with some questions asked of only $50 \%$ of the cohort for the first 6 months of enrollment. Completion and missing-data rates were similar for both questionnaire versions. $^{23}$

\section{Exclusions}

By August 2011, 5,917 women were enrolled in the study. For this analysis, we excluded 1,152 women who had been trying to conceive for more than six cycles at enrollment, 596 women without a verified cycle length who did not complete any follow-up questionnaire, 134 with insufficient information to calculate cycle length, and 141 who were pregnant at entry. In addition, we excluded parous women $(\mathrm{n}=1,281)$ to avoid confounding by unmeasured or unknown factors related to pregnancy and childbirth that could have influenced menstrual cycle characteristics. The final sample included 2,613 participants. In each model, a small number of these participants were excluded because of missing information.

\section{Definition of menstrual function outcomes}

The outcomes examined in this analysis included cycle regularity, cycle length (short and long), duration of menstrual bleeding, and amount of menstrual flow, on the basis of selfreported menstrual history from the baseline questionnaire. Women who responded "yes" to the question "Are your menstrual periods regular, eg, you can usually predict about when your next period will start?" were considered to have regular periods. Cycle length, defined as the number of days from the first day of one menstrual period to the first day of the next menstrual period, was assessed only among women with regular periods. Women reported their usual cycle length when not using hormonal contraception. On the basis of the distribution of cycle length in our population and definitions used previously, ${ }^{6,11,14-18,21,25-27}$ we defined short cycles as $\leq 25$ days and long cycles as $\geq 33$ days. We assessed duration of bleeding only among women with regular menstrual cycles. Participants who reported menstrual flow lasting $\geq 5$ days ("How many days does your period usually flow [bleeding not spotting]?") were classified as having long menstruation duration. This definition was based on the median number of bleeding days in this cohort and in a previous study of women with regular cycles. ${ }^{28}$ Heavy menstrual flow, assessed on the long form of the questionnaire in all women regardless of regularity, was defined as using $\geq 21$ pads or tampons during the entire menses.

\section{Definition of exposures}

Data on age, height, weight, physical activity, smoking, and alcohol and caffeine intake were self-reported on the baseline questionnaire. Body mass index (BMI) was computed as weight $(\mathrm{kg})$ divided by height squared $\left(\mathrm{m}^{2}\right)$ and categorized as $<20 \mathrm{~kg} / \mathrm{m}^{2}, 20-24 \mathrm{~kg} / \mathrm{m}^{2}$ (reference group), $25-29 \mathrm{~kg} / \mathrm{m}^{2}$, and $\geq 30 \mathrm{~kg} / \mathrm{m}^{2}$. Self-reported BMI had excellent agreement with early pregnancy BMI from the Danish Birth Registry. ${ }^{29}$ Physical activity was measured in metabolic equivalents (METs) per week over the past year. We estimated total METs by summing the METs for moderate activity (hours per week multiplied by 3.5 ) and vigorous activity (hours per week multiplied by 7.0), ${ }^{30}$ and categorized physical activity as $<5$ METs, 5-9 METs, 10-19 METs, 20-39 METs, or $\geq 40$ METs per week. Alcohol consumption was measured as drinks per week over the past month, categorized as none, 1-2 drinks, 3-6 drinks, $7-13$ drinks, or $\geq 14$ drinks per week. Current smoking was reported as cigarettes smoked per day and was categorized as none, $<1$ cigarette, $1-9$ cigarettes, and $\geq 10$ cigarettes per day. Caffeine consumption ( $<100 \mathrm{mg} /$ day, 100-199 mg/day, 200-299 mg/day, or $\geq 300 \mathrm{mg} /$ day) was calculated on the basis of consumption of cups of regular and decaffeinated coffee (number of cups of coffee multiplied by $141 \mathrm{mg}$, cups of decaf multiplied by $5 \mathrm{mg}$ ), cups of tea (cups of tea multiplied by $56 \mathrm{mg}$ ) and bottles of cola (regular cola multiplied by $51 \mathrm{mg}$, light cola multiplied by $66 \mathrm{mg}$ ) per week in the past month. ${ }^{31}$ 


\section{Data analysis}

We examined the association between each correlate and the four menstrual cycle outcomes using contingency tables and stratified analyses. We then used bivariate and multivariate log-binomial regression models to estimate prevalence ratios (PRs) and 95\% confidence intervals (CIs) relating selected factors to menstrual cycle regularity and to duration and intensity of flow. ${ }^{32}$ We fit a multinomial logistic regression model to obtain odds ratios in order to examine the association of each independent variable with short ( $\leq 25$ days) and long ( $\geq 33$ days) cycle length, relative to normal cycle length (26-32 days). Because short and long cycles were relatively rare in this cohort ( $<10 \%$ prevalence), the odds ratio provided a reasonable approximation of the PR. Multivariate analyses for each correlate were adjusted for all other correlates and last method of contraception. We also created a variable to evaluate the combined effect of BMI and physical activity (METs per week) on menstrual cycle characteristics. The combined variable was entered in multivariate models and adjusted for the same covariates.

We also evaluated the associations after restricting the study population to women trying to conceive for $<3$ months at study entry and to women who reported a nonhormonal method of last contraception. All analyses were carried out using SAS statistical software version 9.2 (SAS Institute Inc, Cary, NC, USA).

\section{Results}

Of the 2,613 nulliparous women in the cohort, $25.6 \%$ reported irregular periods and $13.0 \%$ reported heavy or very heavy bleeding. Of the 1,940 who reported regular periods, $7.8 \%$ reported short cycles ( $\leq 25$ days), and $6.9 \%$ reported long cycles ( $\geq 33$ days). Among the 1,881 women with information on menstrual bleeding, $35.8 \%$ menstruated for $\geq 5$ days.

The results for each of the four menstrual cycle outcomes are presented separately. All PRs are mutually adjusted for age, BMI, physical activity, smoking, alcohol and caffeine consumption, and last method of contraception.

\section{Correlates of irregular menstrual cycles}

Sedentary women ( $<5 \mathrm{METs}$ /week of physical activity) had a higher prevalence of irregular periods than did women who engaged in moderate levels of activity (20-39 METs/week) ( $\mathrm{PR}=1.54 ; 95 \% \mathrm{CI}=1.16-2.04)$, whereas the most active women ( $>40 \mathrm{METs} /$ week) had a slightly reduced prevalence of irregular periods $(\mathrm{PR}=0.83 ; 95 \% \mathrm{CI}=0.68-1.02)$ compared with moderately active women (Table 1). In joint analyses of BMI and physical activity, obese sedentary women ( $<10$ METs per week, BMI $\geq 30$ ), had a higher prevalence of irregular cycles compared with women of normal weight who exercised moderately ( $\mathrm{PR}=1.46 ; 95 \%$ $\mathrm{CI}=1.06-2.10$; data not shown). Heavy alcohol consumption ( $\geq 14$ alcoholic drinks per week) was associated with a higher prevalence of irregular periods ( $\mathrm{PR}=1.42 ; 95 \%$ $\mathrm{CI}=0.99-2.05)$ compared with no consumption, but more moderate levels of alcohol had little association with cycle regularity. Older age and smoking were associated with a decreased prevalence of irregular periods. Crude and

Table I Correlates of irregular menstrual periods among nulliparous Danish women enrolled in the Snart-Gravid study $(n=2,613 *)$

\begin{tabular}{|c|c|c|c|}
\hline & $\begin{array}{l}\text { Irregular } \\
\text { period, } \mathrm{n}(\%)\end{array}$ & $\begin{array}{l}\text { Prevalence } \\
\text { ratio }^{\dagger}\end{array}$ & $95 \% \mathrm{Cl}$ \\
\hline \multicolumn{4}{|l|}{ Age (years) } \\
\hline$<25$ & $150(27.0)$ & 1.00 & (reference) \\
\hline $25-29$ & $362(28.5)$ & 1.06 & $0.90-1.25$ \\
\hline $30-34$ & $97(19.4)$ & 0.72 & $0.57-0.91$ \\
\hline $35-40$ & $9(10.7)$ & 0.39 & $0.21-0.74$ \\
\hline \multicolumn{4}{|l|}{ BMI $\left(\mathrm{kg} / \mathrm{m}^{2}\right)$} \\
\hline$<20$ & $109(28.5)$ & 1.09 & $0.91-1.30$ \\
\hline $20-24$ & $347(25.3)$ & 1.00 & (reference) \\
\hline $25-29$ & $94(22.2)$ & 0.84 & $0.69-1.03$ \\
\hline$\geq 30$ & $68(29.2)$ & 1.09 & $0.87-1.35$ \\
\hline \multicolumn{4}{|c|}{ Physical activity (METs) } \\
\hline$<5$ & $37(37.0)$ & 1.54 & $1.16-2.04$ \\
\hline $5-9$ & $52(27.1)$ & 1.08 & $0.84-1.40$ \\
\hline $10-19$ & $200(28.0)$ & 1.15 & $0.97-1.35$ \\
\hline $20-39$ & $230(24.6)$ & 1.00 & (reference) \\
\hline$\geq 40$ & $99(2 \mathrm{I} . \mathrm{I})$ & 0.83 & $0.68-1.02$ \\
\hline \multicolumn{4}{|l|}{ Alcohol (drinks/week) } \\
\hline Does not drink & I8I (26.3) & 1.00 & (reference) \\
\hline $\mathrm{I}-2$ & $174(24.8)$ & 0.95 & $0.79-1.13$ \\
\hline $3-6$ & $183(24.9)$ & 0.99 & $0.83-1.19$ \\
\hline $7-13$ & $60(26.0)$ & 1.09 & $0.85-1.4 I$ \\
\hline$\geq 14$ & $20(35.7)$ & 1.42 & $0.99-2.05$ \\
\hline \multicolumn{4}{|c|}{ Smoking (cigarettes/day) } \\
\hline Does not smoke & $520(26.1)$ & 1.00 & (reference) \\
\hline$<1$ & $40(27.6)$ & 0.98 & $0.75-1.29$ \\
\hline $1-9$ & $28(23.1)$ & 0.85 & $0.6 \mathrm{I}-1.18$ \\
\hline$\geq 10$ & $30(19.2)$ & 0.69 & $0.49-0.96$ \\
\hline \multicolumn{4}{|l|}{ Caffeine (mg/day) } \\
\hline$<100$ & 380 (26.9) & 1.00 & (reference) \\
\hline $100-199$ & $127(24.8)$ & 0.97 & $0.8 I-I .15$ \\
\hline $200-299$ & 57 (21.9) & 0.90 & $0.71-1.16$ \\
\hline$\geq 300$ & $54(23.9)$ & 1.05 & $0.82-1.36$ \\
\hline
\end{tabular}

Notes: *We excluded women with missing information on cycle regularity $(n=6)$ and missing covariate information $(n=196)$; ${ }^{\dagger}$ mutually adjusted for all other covariates and most recent method of birth control.

Abbreviations: $\mathrm{n}$, number; $\mathrm{Cl}$, confidence interval; $\mathrm{BMI}$, body mass index; METs, metabolic equivalents. 
adjusted results were similar, indicating little confounding of these associations.

\section{Correlates of short and long menstrual cycle length}

Among women with regular cycles, older age (35-40 years) and smoking ( $\geq 10$ cigarettes/day) were associated with increases in the prevalence of short cycle length $(\mathrm{PR}=1.61 ; 95 \% \mathrm{CI}=0.70-3.68$ and $\mathrm{PR}=1.40 ; 95 \%$ $\mathrm{CI}=0.75-2.59$, respectively) (Table 2). Obese women, compared with those of normal weight, were more likely to have short cycles ( $\mathrm{PR}=1.52 ; 95 \% \mathrm{CI}=0.86-2.69$ ). Except for BMI, few factors were consistently associated with long menstrual cycles. The prevalence of long cycles increased monotonically across the categories of BMI, with the heaviest women being more likely to report cycles of $\geq 33$ days ( $P R=1.86 ; 95 \% \mathrm{CI}=1.05-3.28$ ). Increasing age and heavy alcohol use were associated with a lower prevalence of long cycles, whereas higher caffeine intake was associated with a slight increase in the prevalence of long cycles.

\section{Correlates of long menstrual flow duration}

Among women who reported regular periods, age was inversely associated with the prevalence of long flow duration, with the lowest prevalence found among women aged 35-40 years $(\mathrm{PR}=0.55 ; 95 \% \mathrm{CI}=0.34-0.87)$ (Table 3$)$.

Table 2 Correlates of short and long menstrual cycle length among nulliparous Danish women in the Snart-Gravid study $(\mathrm{n}=1,940 *)$

\begin{tabular}{|c|c|c|c|c|c|c|}
\hline & $\begin{array}{l}\text { Short cycle } \\
\text { ( } \leq 25 \text { days), } n \text { (\%) }\end{array}$ & $\begin{array}{l}\text { Short cycle } \\
\text { prevalence ratio }^{\dagger}\end{array}$ & $95 \% \mathrm{Cl}$ & $\begin{array}{l}\text { Long cycle } \\
\text { ( } \geq 33 \text { days), n (\%) }\end{array}$ & $\begin{array}{l}\text { Long cycle } \\
\text { prevalence ratio }{ }^{\dagger}\end{array}$ & $95 \% \mathrm{Cl}$ \\
\hline \multicolumn{7}{|l|}{ Age (years) } \\
\hline$<25$ & $29(7.1)$ & 1.00 & (reference) & $32(7.9)$ & 1.00 & (reference) \\
\hline $25-29$ & $68(7.5)$ & 1.03 & $0.65-1.65$ & 71 (7.8) & 1.02 & $0.65-1.59$ \\
\hline $30-34$ & $32(7.9)$ & 0.99 & $0.57-1.73$ & $20(4.9)$ & 0.64 & $0.35-1.16$ \\
\hline $35-40$ & $10(13.3)$ & $1.6 \mathrm{I}$ & $0.70-3.68$ & I (I.3) & 0.17 & $0.02-1.31$ \\
\hline \multicolumn{7}{|l|}{ BMI $\left(\mathrm{kg} / \mathrm{m}^{2}\right)$} \\
\hline$<20$ & $18(6.6)$ & 0.88 & $0.52-|.5|$ & $16(5.9)$ & 0.87 & $0.49-1.54$ \\
\hline $20-24$ & $82(8.0)$ & 1.00 & (reference) & $65(6.3)$ & 1.00 & (reference) \\
\hline $25-29$ & $22(6.7)$ & 0.85 & $0.52-1.40$ & $25(7.6)$ & 1.17 & $0.72-1.90$ \\
\hline$\geq 30$ & $17(10.3)$ & 1.52 & $0.86-2.69$ & $18(10.9)$ & 1.86 & $1.05-3.28$ \\
\hline \multicolumn{7}{|c|}{ Physical activity (METs) } \\
\hline$<5$ & $6(9.5)$ & 1.08 & $0.44-2.70$ & $3(4.8)$ & 0.66 & $0.19-2.23$ \\
\hline $5-9$ & $8(5.7)$ & 0.70 & $0.32-1.52$ & $10(7.1)$ & 1.02 & $0.49-2.11$ \\
\hline $10-19$ & $35(6.8)$ & 0.87 & $0.55-1.36$ & $44(8.6)$ & 1.37 & $0.88-2.14$ \\
\hline $20-39$ & $56(7.9)$ & 1.00 & (reference) & $44(6.2)$ & 1.00 & (reference) \\
\hline$\geq 40$ & $34(9.2)$ & 1.21 & $0.77-1.90$ & $23(6.2)$ & 1.01 & $0.60-1.72$ \\
\hline \multicolumn{7}{|c|}{ Alcohol (drinks/week) } \\
\hline Does not drink & $34(6.7)$ & 1.00 & (reference) & $35(6.9)$ & 1.00 & (reference) \\
\hline $\mathrm{I}-2$ & $4 \mid(7.8)$ & 1.20 & $0.74-1.93$ & $4 \mid(7.9)$ & 1.15 & $0.7 I-1.86$ \\
\hline $3-6$ & $45(8.1)$ & 1.21 & $0.75-1.95$ & $39(7.1)$ & 1.11 & $0.68-1.82$ \\
\hline $7-13$ & $17(9.9)$ & 1.50 & $0.79-2.82$ & $8(4.7)$ & 0.72 & $0.32-1.61$ \\
\hline$\geq 14$ & $2(5.6)$ & 0.67 & $0.15-3.03$ & $\mathrm{I}(2.8)$ & 0.41 & $0.05-3.12$ \\
\hline \multicolumn{7}{|c|}{ Smoking (cigarettes/day) } \\
\hline Does not smoke & II 4 (7.8) & 1.00 & (reference) & $102(6.9)$ & 1.00 & (reference) \\
\hline$<1$ & $3(2.9)$ & 0.32 & $0.10-1.03$ & $8(7.6)$ & 1.06 & $0.49-2.28$ \\
\hline $1-9$ & $8(8.6)$ & 1.02 & $0.47-2.22$ & $5(5.4)$ & 0.68 & $0.26-1.76$ \\
\hline$\geq 10$ & $14(1 \mathrm{I} .1)$ & 1.40 & $0.75-2.59$ & $9(7.1)$ & 0.97 & $0.46-2.03$ \\
\hline \multicolumn{7}{|l|}{ Caffeine (mg/day) } \\
\hline$<100$ & 71 (6.9) & 1.00 & (reference) & $76(7.4)$ & 1.00 & (reference) \\
\hline $100-199$ & $30(7.8)$ & 1.10 & $0.70-1.74$ & $21(5.4)$ & 0.78 & $0.47-1.30$ \\
\hline $200-299$ & $21(10.3)$ & 1.50 & $0.87-2.59$ & $16(7.9)$ & 1.38 & $0.77-2.49$ \\
\hline$\geq 300$ & $17(9.9)$ & 1.36 & $0.74-2.5 \mathrm{I}$ & II (6.4) & 1.16 & $0.58-2.33$ \\
\hline
\end{tabular}

Notes: *We excluded women with missing covariate information $(n=147) ;{ }^{\dagger}$ mutually adjusted for all other covariates and most recent method of birth control. Abbreviations: $\mathrm{n}$, number; $\mathrm{Cl}$, confidence interval; BMI, body mass index; METs, metabolic equivalents. 
Obesity, extremes of physical activity, and smoking were associated with slight increases in the prevalence of longer flow. Alcohol drinkers had a lower prevalence of long menstrual flow compared with nondrinkers, but the associations were similar for higher levels of drinking (PRs ranging from 0.69-0.95).

\section{Correlates of heavy menstrual bleeding}

Relative to heavy-bleeding rates in women with a normal BMI (20-24 kg/m²), the prevalence of heavy bleeding

Table 3 Correlates of long menstrual flow duration compared with normal menstrual flow duration among nulliparous Danish women in the Snart-Gravid study $(\mathrm{n}=1,940 *)$

\begin{tabular}{|c|c|c|c|}
\hline & $\begin{array}{l}\text { Menstruation } \\
\text { duration } \\
\text { ( } \geq 5 \text { days), n (\%) }\end{array}$ & $\begin{array}{l}\text { Prevalence } \\
\text { ratio }^{\dagger}\end{array}$ & $95 \% \mathrm{Cl}$ \\
\hline \multicolumn{4}{|l|}{ Age (years) } \\
\hline$<25$ & $158(38.9)$ & 1.00 & (reference) \\
\hline $25-29$ & $326(35.9)$ & 0.93 & $0.80-1.09$ \\
\hline $30-34$ & $132(32.7)$ & 0.86 & $0.7 \mid-1.04$ \\
\hline $35-40$ & $16(21.3)$ & 0.55 & $0.34-0.87$ \\
\hline \multicolumn{4}{|l|}{$\mathrm{BMI}\left(\mathrm{kg} / \mathrm{m}^{2}\right)$} \\
\hline$<20$ & II $3(41.4)$ & 1.21 & $1.03-1.43$ \\
\hline $20-24$ & $338(33.0)$ & 1.00 & (reference) \\
\hline $25-29$ & $114(34.7)$ & 1.03 & $0.87-1.22$ \\
\hline$\geq 30$ & $67(40.6)$ & 1.17 & $0.95-1.45$ \\
\hline \multicolumn{4}{|c|}{ Physical activity (METs) } \\
\hline$<5$ & $25(39.7)$ & 1.22 & $0.88-1.69$ \\
\hline $5-9$ & $54(38.6)$ & 1.14 & $0.90-1.45$ \\
\hline $10-19$ & $195(37.9)$ & 1.21 & $1.04-1.42$ \\
\hline $20-39$ & $219(31.1)$ & 1.00 & (reference) \\
\hline$\geq 40$ & $139(37.5)$ & 1.21 & $1.02-1.44$ \\
\hline \multicolumn{4}{|c|}{ Alcohol (drinks/week) } \\
\hline Does not drink & $207(4 I .0)$ & 1.00 & (reference) \\
\hline $\mathrm{I}-2$ & $189(35.9)$ & 0.87 & $0.75-1.02$ \\
\hline $3-6$ & $175(31.7)$ & 0.78 & $0.66-0.92$ \\
\hline $7-13$ & $47(27.5)$ & 0.69 & $0.53-0.91$ \\
\hline$\geq 14$ & $14(38.9)$ & 0.95 & $0.62-1.46$ \\
\hline \multicolumn{4}{|c|}{ Smoking (cigarettes/day) } \\
\hline Does not smoke & $517(35.2)$ & 1.00 & (reference) \\
\hline$<1$ & $37(35.2)$ & 1.09 & $0.83-1.43$ \\
\hline $1-9$ & $29(3 \mid .2)$ & 0.87 & $0.64-1.19$ \\
\hline$\geq 10$ & 49 (38.9) & 1.08 & $0.86-1.37$ \\
\hline \multicolumn{4}{|l|}{ Caffeine (mg/day) } \\
\hline$<100$ & $374(36.2)$ & 1.00 & (reference) \\
\hline $100-199$ & $134(34.8)$ & 1.04 & $0.88-1.22$ \\
\hline $200-299$ & $65(32.0)$ & 1.00 & $0.8 \mathrm{I}-\mathrm{I} .25$ \\
\hline$\geq 300$ & $59(34.3)$ & 1.13 & $0.90-1.43$ \\
\hline
\end{tabular}

Notes: *We excluded women with missing information on duration of menstruation $(n=3)$ and with missing covariate information $(n=145)$; ${ }^{\dagger}$ mutually adjusted for all other covariates and most recent method of birth control.

Abbreviations: $\mathrm{n}$, number; $\mathrm{Cl}$, confidence interval; $\mathrm{BMI}$, body mass index; METs, metabolic equivalents. increased monotonically with a higher BMI category (Table 4). The highest levels of alcohol intake, caffeine intake, and smoking were also associated with increased prevalence of heavy bleeding (by $48 \%, 45 \%$, and $60 \%$, respectively). In contrast, age was inversely associated with the prevalence of heavy menstrual bleeding. Compared with participants aged $<25$ years, participants aged 35-40 years were 29\% less likely to have heavy menstrual bleeding ( $P R=0.71 ; 95 \%$ $\mathrm{CI}=0.34-1.48)$. Neither vigorous nor sedentary physical activity was associated with heavy flow.

Table 4 Correlates of heavy menstrual bleeding compared with normal menstrual bleeding among nulliparous Danish women in the Snart-Gravid study $(\mathrm{n}=\mathrm{I}, 88 \mathrm{I})$

\begin{tabular}{|c|c|c|c|}
\hline & $\begin{array}{l}\text { Heavy } \\
\text { menstruation } \\
\text { (>20 pads), n (\%) }\end{array}$ & $\begin{array}{l}\text { Prevalence } \\
\text { ratio }^{\dagger}\end{array}$ & $95 \% \mathrm{Cl}$ \\
\hline \multicolumn{4}{|l|}{ Age (years) } \\
\hline$<25$ & $67(15.8)$ & 1.00 & (reference) \\
\hline $25-29$ & $116(12.7)$ & 0.80 & $0.60-1.06$ \\
\hline $30-34$ & $47(13.4)$ & 0.82 & $0.58-1.17$ \\
\hline $35-40$ & $7(13.5)$ & $0.7 \mathrm{I}$ & $0.34-1.48$ \\
\hline \multicolumn{4}{|l|}{ BMI $\left(\mathrm{kg} / \mathrm{m}^{2}\right)$} \\
\hline$<20$ & $34(12.4)$ & 1.05 & $0.74-1.5 \mid$ \\
\hline $20-24$ & $116(11.7)$ & 1.00 & (reference) \\
\hline $25-29$ & $44(14.8)$ & 1.25 & $0.90-1.72$ \\
\hline$\geq 30$ & $43(23.6)$ & 2.03 & $1.47-2.80$ \\
\hline \multicolumn{4}{|c|}{ Physical activity (METs) } \\
\hline$<5$ & $12(17.1)$ & 1.02 & $0.59-1.78$ \\
\hline $5-9$ & $17(12.5)$ & 0.81 & $0.50-1.33$ \\
\hline $10-19$ & $75(14.7)$ & 1.10 & $0.82-1.46$ \\
\hline $20-39$ & $84(12.5)$ & 1.00 & (reference) \\
\hline$\geq 40$ & 49 (13.9) & 1.13 & $0.82-1.57$ \\
\hline \multicolumn{4}{|c|}{ Alcohol (drinks/week) } \\
\hline Does not drink & $81(14.6)$ & 1.00 & (reference) \\
\hline $\mathrm{I}-2$ & 59 (11.9) & 0.81 & $0.59-1.11$ \\
\hline $3-6$ & $64(12.8)$ & 0.83 & $0.6 \mathrm{I}-\mathrm{I} .14$ \\
\hline $7-13$ & $24(15.8)$ & 0.94 & $0.6 \mathrm{I}-\mathrm{I} .44$ \\
\hline$\geq 14$ & $9(23.7)$ & 1.48 & $0.80-2.72$ \\
\hline \multicolumn{4}{|c|}{ Smoking (cigarettes/day) } \\
\hline Does not smoke & $186(12.7)$ & 1.00 & (reference) \\
\hline$<1$ & $12(14.1)$ & 1.04 & $0.60-1.80$ \\
\hline $\mathrm{I}-9$ & $12(14.2)$ & 1.03 & $0.60-1.76$ \\
\hline$\geq 10$ & $27(23.5)$ & 1.60 & $1.11-2.30$ \\
\hline \multicolumn{4}{|l|}{ Caffeine (mg/day) } \\
\hline$<100$ & I2I (II.8) & 1.00 & (reference) \\
\hline $100-199$ & $54(14.7)$ & 1.33 & $0.98-1.79$ \\
\hline $200-299$ & $36(18.6)$ & 1.63 & $1 . \mid 6-2.31$ \\
\hline$\geq 300$ & $26(16.7)$ & $\mathrm{I} .45$ & $0.96-2.19$ \\
\hline
\end{tabular}

Notes: *We excluded women with missing information on heaviness of menstruation $(n=2)$ and with missing covariate information $(n=47)$; ${ }^{\dagger}$ mutually adjusted for all other covariates and most recent method of birth control.

Abbreviations: $\mathrm{n}$, number; $\mathrm{Cl}$, confidence interval; $\mathrm{BMI}$, body mass index; METs, metabolic equivalents. 
In secondary analyses, we found that the associations reported in Tables 1-4 did not materially change when the population was restricted to women who had been attempting pregnancy for $<3$ months at study entry $(n=1,770)$ or to women whose last method of birth control was nonhormonal $(\mathrm{n}=814)$ (data not shown).

Figure 1 provides a qualitative summary of the correlates of the menstrual factors examined in this analysis. Comparisons were made between the most extreme category of each characteristic and the reference category.

\section{Discussion}

In this study of nulliparous pregnancy planners, we found that age, sedentary behavior, and BMI had the strongest and most consistent associations with menstrual cycle patterns. We also found several associations between high alcohol consumption and menstrual patterns, but these were based on small numbers and were inconsistent across exposure categories. Similar to results from other studies of women in the same age range, ${ }^{33-36}$ our results suggest that women in their thirties have a lower prevalence of irregular cycles than do women in their twenties. Also consistent with our findings, results from several other studies indicate that age is associated with shorter menstrual cycle length, ${ }^{6,14,17,18,27}$ shorter duration of bleeding, ${ }^{35}$ and lighter flow. ${ }^{37}$

Our data extend previous research ${ }^{11,12}$ by evaluating menstrual characteristics in a population of women with a broad range of physical activity levels. We found that low levels of physical activity ( $<5 \mathrm{METs} /$ week) had the strongest association with irregular periods, a finding that to our knowledge has not been reported previously. We also found that women who were both obese and sedentary had a higher prevalence of irregular periods compared with normal-weight women who exercised moderately. Overall, we found little consistency in associations between higher levels of physical activity and menstrual characteristics.

Excess adipose tissue may affect levels of androgens and estrogens through several pathways: it may provide a reservoir for lipid-soluble steroids; $;^{13,38}$ and it may affect the relations between hormones and sex-hormone-binding globulin. ${ }^{13,16,38,39}$ Our study is consistent with most, ${ }^{14-16,25}$ but not all, ${ }^{17}$ previous studies that found increases in long cycle length with increasing BMI. Obesity was also associated with a two-fold increase in the prevalence of heavy menstrual flow, which has been reported previously. ${ }^{10}$ Excessive blood loss has been associated with ovulatory disorders, ${ }^{38}$ which are more common among obese women and may be related to underlying hormonal irregularities, such as hyperandrogenemia.

Our study is also consistent with previous studies indicating that smokers have an increased prevalence of short cycles $^{14,18,26,27}$ and heavier menses ${ }^{20,40}$ compared with nonsmokers. However, our results disagree with previous studies that found a higher prevalence of irregular cycles among smokers. ${ }^{14,18,20,26}$ Smoking has been consistently associated with lower estrogen ${ }^{9,38,39}$ and higher follicle stimulating hormone levels, ${ }^{41}$ which in turn may increase menstrual bleeding and shorten menstrual cycles, suggesting biological plausibility for the association between smoking and heavy bleeding and short cycles.

\begin{tabular}{|c|c|c|c|c|c|c|c|}
\hline & Age & BMI & $\begin{array}{l}\text { Sedentary } \\
\text { activity (<5 } \\
\text { METs) }\end{array}$ & $\begin{array}{l}\text { High } \\
\text { activity (40+ } \\
\text { METs) }\end{array}$ & $\begin{array}{l}\text { Alcohol } \\
\text { consumption }\end{array}$ & Smoking & $\begin{array}{l}\text { Caffeine } \\
\text { consumption }\end{array}$ \\
\hline Irregular period & $\downarrow \downarrow$ & - & 个个 & $\downarrow$ & 个个 & $\downarrow \downarrow$ & - \\
\hline Short cycle & $\uparrow \uparrow$ & $\uparrow \uparrow$ & - & $\uparrow$ & $\downarrow \downarrow$ & $\uparrow \uparrow$ & 个个 \\
\hline Long cycle & $\downarrow \downarrow$ & 个个 & $\downarrow \downarrow$ & - & $\downarrow \downarrow$ & - & $\uparrow$ \\
\hline $\begin{array}{l}\text { Long menstrual } \\
\text { flow duration }\end{array}$ & $\downarrow \downarrow$ & $\uparrow$ & $\uparrow$ & $\uparrow$ & - & - & $\uparrow$ \\
\hline $\begin{array}{l}\text { Heavy } \\
\text { menstrual } \\
\text { bleeding }\end{array}$ & $\downarrow \downarrow$ & 个个 & - & $\uparrow$ & $\uparrow \uparrow$ & 个个 & 个个 \\
\hline
\end{tabular}

Figure I Summary of the correlates of menstrual cycle function.

Notes: $\uparrow \uparrow$ The most extreme exposure category is associated with a $>30 \%$ increased prevalence of the outcome relative to the reference group; $\uparrow$ The most extreme exposure category is associated with a 10\%-30\% increased prevalence of the outcome compared with the reference group; - the most extreme exposure category is not associated with an increase or decrease in the prevalence of the outcome by more than $10 \%$; $\downarrow$ The most extreme exposure category is associated with a $10 \%-23 \%$ decreased prevalence of the outcome compared with the reference group; $\downarrow \downarrow$ The most extreme exposure category is associated with a $>23 \%$ decreased prevalence of the outcome relative to the reference group.

Abbreviations: BMI, body mass index; METs, metabolic equivalents. 
Alcohol intake may increase levels of testosterone, estradiol, and estrogen in premenopausal women. ${ }^{42-45} \mathrm{In}$ our study, heavy alcohol use ( $\geq 14$ drinks per week) was associated with a higher prevalence of irregular periods and heavy bleeding. All levels of drinking, compared with nondrinking, slightly decreased the prevalence of long bleeding duration. Our results are difficult to compare with previous studies that found a lower prevalence of long ${ }^{15,17}$ or irregular ${ }^{15}$ cycles among drinkers, because the latter assessed dichotomous levels of alcohol consumption (any consumption versus none), and one study assessed exposure among women in their $60 \mathrm{~s}$ and $70 \mathrm{~s}$, long after the collection of data on menstrual cycle factors. ${ }^{15}$

To our knowledge, only two previous studies have evaluated caffeine and menstrual function. ${ }^{15,21}$ Fenster et $\mathrm{al}^{21}$ found, as we did, that high caffeine intake was associated with a higher prevalence of short cycles. Findings on bleeding duration have been inconsistent, with one study reporting shorter duration of menstruation with increased caffeine consumption, ${ }^{21}$ and the other finding little effect of caffeine on bleeding duration. ${ }^{15}$ We found that higher caffeine consumers had a higher prevalence of heavier bleeding than those drinking $<100 \mathrm{mg} /$ day, which to our knowledge has not been reported before. Biological mechanisms related to caffeine consumption and hormones that affect menstruation may involve changes in total and free estradiol levels. ${ }^{46}$

The main limitations of our study are the cross-sectional nature of the data and the lack of a defined reference period for menstrual cycle outcomes. We instructed participants to report their usual menstrual characteristics when not using hormonal contraceptives. Although it is possible that recent hormonal contraception use could impact the observed menstrual patterns, we found that estimates were similar with and without controlling for the last method of birth control, suggesting that recent hormonal contraceptive use did not confound our results. We also found similar results when we restricted the analyses to women who had used nonhormonal contraception as their most recent method of birth control. Despite the lack of a defined reference period for menstrual outcomes, we expect that the month-to-month menstrual cycle patterns of the women in the cohort would be stable because of the relatively young and narrow age range. ${ }^{35}$ Additionally, we were unable to examine the effect of endocrine-disrupting compounds or xenoestrogens that have been suggested to affect hormonally sensitive functions like the menstrual cycle. ${ }^{47-50}$

The factors we assessed may differ between pregnancy planners and women not planning pregnancy, especially if women planning pregnancy believe that altering their behavior (eg, decreasing smoking or alcohol or caffeine consumption) would increase their fecundability or improve birth outcomes. Such behavioral changes might limit our ability to validly estimate the associations between more intense levels of these exposures and menstrual cycle factors, because there are fewer women at the extreme levels of exposure. When we restricted the analyses to women who had been trying to conceive for three cycles or less at baseline and who may not have made any drastic changes to their behaviors, we found similar results, implying that this type of bias was unlikely to have had a major effect. Pregnancy planners may also be healthier in other ways that could affect the results reported here.

We did not validate the accuracy of the menstrual-function variables in our study population. A previous validation study found that $57 \%$ of women reported usual cycle lengths within 2 days of their mean cycle length. ${ }^{51}$ Correct estimation of menstrual cycle length depends on many individual factors, but one study suggested that sexually active women who are trying to conceive may be more accurate in their reports. ${ }^{52}$ Another study indicated that self-report may provide a better summary of usual cycle length than menstruation diaries or calendars covering $<2$ months. ${ }^{51} \mathrm{~A}$ subanalysis of participants from our cohort found modest agreement between menstrual cycle lengths reported on the baseline questionnaire and a subsequent follow-up questionnaire $(k=0.60) .{ }^{9}$ Outcome misclassification is also a concern for reports of duration of menstrual bleeding and heaviness of flow. Previous studies found that when women had reported blood loss as heavy, their flow was actually within the normal range as determined by measurement of actual blood loss collected from pads and tampons. ${ }^{37,53}$ In our study, we asked participants to report flow heaviness on the basis of the number of sanitary products used per cycle. Although this would eliminate some of the problems with a strictly qualitative measure of flow heaviness, some misclassification is likely.

\section{Conclusion}

In summary, our study is one of the first to evaluate determinants of duration and heaviness of menstrual flow and to evaluate sedentary behavior in relation to the menstrual cycle. Despite differences in study designs, our results generally agree with previous studies that suggest that age, BMI, smoking, caffeine, and alcohol may affect menstrual cycle characteristics. Sedentary behavior was associated with an increased prevalence of irregular cycles, but high levels of physical activity were not strongly related to any menstrual cycle characteristic. 


\section{Acknowledgments}

We are grateful to Tina Christensen for her support in data collection and media contacts, Donna Day Baird for her feedback on questionnaire development, Obi Chidi for his preliminary work on exposure categorization, and Thomas Jensen for his assistance with website and questionnaire design.

\section{Disclosure}

This study was supported by the National Institute of Child Health and Human Development (R21050264) and the Danish Medical Research Council (271-07-0338). The authors report no conflicts of interest in this work.

\section{References}

1. Harlow SD, Ephross SA. Epidemiology of menstruation and its relevance to women's health. Epidemiol Rev. 1995;17(2):265-286.

2. Jensen JT, Speroff L. Health benefits of oral contraceptives. Obstet Gynecol Clin North Am. 2000;27(4):705-721.

3. Barrett-Connor E, Bush TL. Estrogen and coronary heart disease in women. JAMA. 1991;265(14):1861-1867.

4. Bertuccio P, Tavani A, Gallus S, Negri E, La Vecchia C. Menstrual and reproductive factors and risk of non-fatal acute myocardial infarction in Italy. Eur J Obstet Gynecol Reprod Biol. 2007;134(1):67-72.

5. Butler LM, Potischman NA, Newman B, et al. Menstrual risk factors and early-onset breast cancer. Cancer Causes Control. 2000;11(5):451-458.

6. Olsson H, Landin-Olsson M, Gullberg B. Retrospective assessment of menstrual cycle length in patients with breast cancer, in patients with benign breast disease, and in women without breast disease. $J$ Natl Cancer Inst. 1983;70(1):17-20.

7. Titus-Ernstoff L, Longnecker MP, Newcomb PA, et al. Menstrual factors in relation to breast cancer risk. Cancer Epidemiol Biomarkers Prev. 1998;7(9):783-789.

8. Titus-Ernstoff L, Perez K, Cramer DW, Harlow BL, Baron JA, Greenberg ER. Menstrual and reproductive factors in relation to ovarian cancer risk. Br J Cancer. 2001;84(5):714-721.

9. Wise LA, Mikkelsen EM, Rothman KJ, et al. A prospective cohort study of menstrual characteristics and time to pregnancy. Am J Epidemiol. 2011;174(6):701-709.

10. Santos IS, Minten GC, Valle NC, et al. Menstrual bleeding patterns: a community-based cross-sectional study among women aged 18-45 years in Southern Brazil. BMC Womens Health. 2011;11(1):26.

11. Sternfeld B, Jacobs MK, Quesenberry CP Jr, Gold EB, Sowers M. Physical activity and menstrual cycle characteristics in two prospective cohorts. Am J Epidemiol. 2002;156(5):402-409.

12. Frisch RE. Body fat, menarche, fitness and fertility. Hum Reprod. 1987;2(6):521-533.

13. Pasquali R, Pelusi C, Genghini S, Cacciari M, Gambineri A. Obesity and reproductive disorders in women. Hum Reprod Update. 2003;9(4):359-372.

14. Rowland AS, Baird DD, Long S, et al. Influence of medical conditions and lifestyle factors on the menstrual cycle. Epidemiology. 2002;13(6):668-674.

15. Cooper GS, Sandler DP, Whelan EA, Smith KR. Association of physical and behavioral characteristics with menstrual cycle patterns in women age 29-31 years. Epidemiology. 1996;7(6):624-628.

16. Wei S, Schmidt MD, Dwyer T, Norman RJ, Venn AJ. Obesity and menstrual irregularity: associations with SHBG, testosterone, and insulin. Obesity (Silver Spring). 2009;17(5):1070-1076.

17. Liu Y, Gold EB, Lasley BL, Johnson WO. Factors affecting menstrual cycle characteristics. Am J Epidemiol. 2004;160(2):131-140.
18. Kato I, Toniolo P, Koenig KL, et al. Epidemiologic correlates with menstrual cycle length in middle aged women. Eur J Epidemiol. 1999;15(9):809-814.

19. Windham GC, Mitchell P, Anderson M, Lasley BL. Cigarette smoking and effects on hormone function in premenopausal women. Environ Health Perspect. 2005;113(10):1285-1290.

20. Mishra GD, Dobson AJ, Schofield MJ. Cigarette smoking, menstrual symptoms and miscarriage among young women. Aust N Z J Public Health. 2000;24(4):413-420.

21. Fenster L, Quale C, Waller K, et al. Caffeine consumption and menstrual function. Am J Epidemiol. 1999;149(6):550-557.

22. Mikkelsen EM, Hatch EE, Wise LA, Rothman KJ, Riis A, Sørensen HT. Cohort profile: the Danish Web-based Pregnancy Planning Study 'Snart-Gravid'. Int J Epidemiol. 2009;38(4):938-943.

23. Rothman KJ, Mikkelsen EM, Riis A, Sørensen HT, Wise LA, Hatch EE. Randomized trial of questionnaire length. Epidemiology. 2009; 20(1): 154

24. Huybrechts KF, Mikkelsen EM, Christensen T, et al. A successful implementation of e-epidemiology: the Danish pregnancy planning study 'Snart-Gravid'. Eur J Epidemiol. 2010;25(5):297-304.

25. Harlow SD, Matanoski GM. The association between weight, physical activity, and stress and variation in the length of the menstrual cycle. Am J Epidemiol. 1991;133(1):38-49.

26. Windham GC, Elkin EP, Swan SH, Waller KO, Fenster L. Cigarette smoking and effects on menstrual function. Obstet Gynecol. 1999; 93(1):59-65.

27. Lawson CC, Whelan EA, Lividoti Hibert EN, Spiegelman D, Schernhammer ES, Rich-Edwards JW. Rotating shift work and menstrual cycle characteristics. Epidemiology. 2011;22(3):305-312.

28. Dasharathy SS, Mumford SL, Pollack AZ, et al. Menstrual bleeding patterns among regularly menstruating women. Am J Epidemiol. 2012;175(6):536-545.

29. Wise LA, Rothman KJ, Mikkelsen EM, Sørensen HT, Riis A, Hatch EE. An internet-based prospective study of body size and time-to-pregnancy. Hum Reprod. 2010;25(1):253-264.

30. Jacobs DR Jr, Ainsworth BE, Hartman TJ, Leon AS. A simultaneous evaluation of 10 commonly used physical activity questionnaires. Med Sci Sports Exerc. 1993;25(1):81-91.

31. Center for Science in the Public Interest. Caffeine content of food and drugs [webpage on the Internet]. Washington, DC: Center for Science in the Public Interest; 2012. Available from: http://www.cspinet.org/ new/cafchart.htm. Accessed August 24, 2011.

32. Spiegelman D, Hertzmark E. Easy SAS calculations for risk or prevalence ratios and differences. Am J Epidemiol. 2005;162(3):199-200.

33. Chiazze L Jr, Brayer FT, Macisco JJ Jr, Parker MP, Duffy BJ. The length and variability of the human menstrual cycle. JAMA. 1968;203(6):377-380.

34. Treloar AE, Boynton RE, Behn BG, Brown BW. Variation of the human menstrual cycle through reproductive life. Int J Fertil. 1967;12(1 Pt 2): 77-126.

35. Matsumoto S, Nogami Y, Okhkuri S. Statistical studies on menstruation: a criticism on the definition of normal menstruation. Gunma J Med Sci. 1962;11:294-318.

36. Vollman RF. The menstrual cycle. Major Probl Obstet Gynecol. 1977;7:1-193.

37. Hallberg L, Högdahl AM, Nilsson L, Rybo G. Menstrual blood loss a population study. Variation at different ages and attempts to define normality. Acta Obstet Gynecol Scand. 1966;45(3):320-351.

38. Harlow SD. Menstruation and menstrual disorders: the epidemiology of menstruation and menstrual dysfunction. In: Goldman MB, Hatch MC, editors. Women and Health. San Diego, CA: Academic Press; 2000:99-113.

39. Lucero J, Harlow BL, Barbieri RL, Sluss P, Cramer DW. Early follicular phase hormone levels in relation to patterns of alcohol, tobacco, and coffee use. Fertil Steril. 2001;76(4):723-729.

40. Hornsby PP, Wilcox AJ, Weinberg CR. Cigarette smoking and disturbance of menstrual function. Epidemiology. 1998;9(2):193-198. 
41. Whitcomb BW, Bodach SD, Mumford SL, et al. Ovarian function and cigarette smoking. Paediatr Perinat Epidemiol. 2010;24(5):433-440.

42. Maskarinec G, Morimoto Y, Takata Y, Murphy SP, Stanczyk FZ Alcohol and dietary fibre intakes affect circulating sex hormones among premenopausal women. Public Health Nutr. 2006;9(7):875-881.

43. Reichman ME, Judd JT, Longcope C, et al. Effects of alcohol consumption on plasma and urinary hormone concentrations in premenopausal women. J Natl Cancer Inst. 1993;85(9):722-727.

44. Rinaldi S, Peeters PH, Bezemer ID, et al. Relationship of alcohol intake and sex steroid concentrations in blood in pre- and post-menopausal women: the European Prospective Investigation into Cancer and Nutrition. Cancer Causes Control. 2006;17(8):1033-1043.

45. Muti P, Trevisan M, Micheli A, et al. Alcohol consumption and total estradiol in premenopausal women. Cancer Epidemiol Biomarkers Prev. 1998;7(3):189-193.

46. Schliep KC, Schisterman EF, Mumford SL, et al. Caffeinated beverage intake and reproductive hormones among premenopausal women in the BioCycle Study. Am J Clin Nutr. 2012;95(2):488-497.

47. Eskenazi B, Warner M, Mocarelli P, et al. Serum dioxin concentrations and menstrual cycle characteristics. Am J Epidemiol. 2002;156(4):383-392.
48. United Nations Environment Programme, World Health Organization. State of the science of endocrine disrupting chemicals - 2012. Geneva, Switzerland: United Nations Environment Programme and the World Health Organization; 2013. Available from: http://www.who.int/iris/ bitstream/10665/78101/1/9789241505031_eng.pdf. Accessed May 9, 2013.

49. Nicolopoulou-Stamati P, Pitsos MA. The impact of endocrine disrupters on the female reproductive system. Hum Reprod Update. 2001;7(3):323-330.

50. Diamanti-Kandarakis E, Bourguignon JP, Giudice LC, et al. Endocrinedisrupting chemicals: an Endocrine Society scientific statement. Endocr Rev. 2009;30(4):293-342.

51. Small CM, Manatunga AK, Marcus M. Validity of self-reported menstrual cycle length. Ann Epidemiol. 2007;17(3):163-170.

52. Jukic AM, Weinberg CR, Wilcox AJ, McConnaughey DR, Hornsby P, Baird DD. Accuracy of reporting of menstrual cycle length. Am J Epidemiol. 2008;167(1):25-33.

53. Fraser IS, McCarron G, Markham R. A preliminary study of factors influencing perception of menstrual blood loss volume. Am J Obstet Gynecol. 1984;149(7):788-793.
Clinical Epidemiology

\section{Publish your work in this journal}

Clinical Epidemiology is an international, peer-reviewed, open access journal focusing on disease and drug epidemiology, identification of risk factors and screening procedures to develop optimal preventative initiatives and programs. Specific topics include: diagnosis, prognosis, treatment, screening, prevention, risk factor modification, systematic

Submit your manuscript here: http://www.dovepress.com/clinical-epidemiology-journal

\section{Dovepress}

reviews, risk \& safety of medical interventions, epidemiology \& biostatical methods, evaluation of guidelines, translational medicine, health policies \& economic evaluations. The manuscript management system is completely online and includes a very quick and fair peer-review system, which is all easy to use. 